\title{
COVID-19: An Insult to Injury on Equity
}

\author{
Biljana Parapid ${ }^{1}$ (i) and Rachel M. Bond ${ }^{2,3}$ (1) \\ Belgrade University School of Medicine, Division of Cardiology University Clinical Center of Serbia,' Belgrade - Serbia \\ Dignity Health System, Division of Cardiology, ${ }^{2}$ Chandler, AZ - USA \\ Creighton University School of Medicine, Division of Internal Medicine, ${ }^{3}$ Omaha, NE - USA
}

SARS-CoV-2, which causes COVID-19, created a pandemic that not only overwhelmed the world in December 2019, but also challenged humanity in every way.

While a significant portion of the global population remained in a standstill, waiting for an end and adapting to limits of all sorts, including working from home, a new workforce category emerged: the "frontline" workers. Doctors, nurses, and all allied professions employed by the healthcare system were joined by a long line of diverse service providers. The latter faced different forms of discrimination from their surroundings, fearing the risk of infection based on high rates of medical misinformation; for the former group, Pandora's box of bias was yet to be opened, in particular for women.

According to initial reports, women were less likely to develop severe or life-threatening forms of SARS-CoV-2 infection. With higher mortality rates seen in men, an assumption that frontline work was safer for women than men quickly emerged. As a result, although scarce, reports confirmed higher infection rates in women frontline healthcare workers, as was seen in Spain. ${ }^{1}$

\section{Keywords}

COVID19; Equity; SARS-CoV-2; Diversity; Inclusion.

Mailing Address: Biljana Parapid, MD, PhD, FESC

Assistant Professor, Department of Internal Medicine - Cardiology

School of Medicine University of Belgrade

Division of Cardiology, University Clinical Center of Serbia

Dr. Subotića, 13. Postal Code: 11000 Beograd - Serbia

Email: biljana_parapid@yahoo.com

DOI: https://doi.org/10.36660/ijcs.20210165

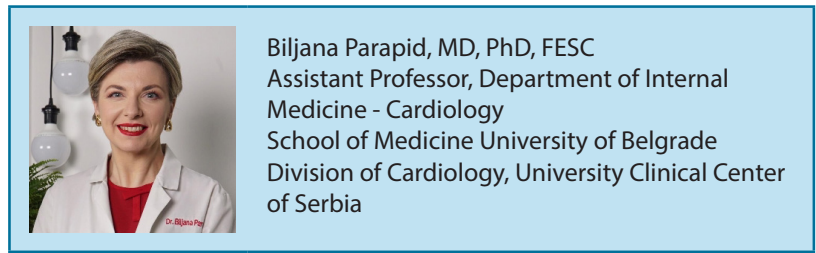

Globally, women occupy $70 \%$ of frontline positions in the healthcare sector. Despite this, they are paid $11 \%$ less than men. ${ }^{2}$ This was reconfirmed during the pandemic, where women physicians and nurses in the United States were paid $12 \%$ and $8 \%$ less than men in the same positions. ${ }^{3}$ Yet, only $25 \%$ of healthcare leadership and decision-making positions have been held by women during the pandemic. ${ }^{4}$

The first warnings came from UN Women in early Spring 2020..$^{5}$ With the significantly higher percentage of women frontline workers, an ongoing crisis will only deepen gaps on the road to achieving equity. This was best highlighted where, simultaneously, various international medical entities ${ }^{6}$ yielded additional attention to the world of academic medicine where tenure clocks were not stopped or even paused, further aggravating promotion pathways for women who had less time to publish. Additionally, while men were not participating in frontline work, they were afforded the opportunity to be lead authors of publications on frontline work and/or ongoing pandemic research. ${ }^{7}$

The existing unpaid workload at home was globally aggravated by the increased need for homeschooling, and, culturally, while dual physician households experienced additional challenges during pandemic work, the toll on women's health were universally greater: from mental health issues to delayed family planning due to menstrual cycle disturbances, ${ }^{8-13}$ even in the absence of contracting the disease itself or while recovering from it.

Finally, as the pandemic has greatly changed our existence, lamenting and reporting well-known data should give way to implementation of actionable solutions.

"Primum non nocere." Medical academic institutions should start by practicing what they preach, beginning

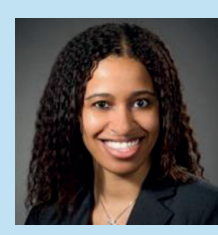

Rachel M.Bond, FACC System Director, Women's Heart Health Dignity Health, Chandler, AZ - USA Creighton University School of Medicine, Division of Internal Medicine, Omaha, NE - USA 
with their employees, the same way they do for their patients, regardless of gender, color, or creed. As women's healthcare policies vary globally, ${ }^{14}$ it is up to the leading medical and scientific authorities of each respective country - regardless of local practice and of whether or not there is a Diversity-Equity-Inclusion officerl vice-dean - to protect their largest frontline workforce. Existing women's heart health programs, centers, and clinics should open their doors on a weekly basis to inhouse staff, who most likely do not have time to schedule an appointment themselves. The potential budgeting issue could be overcome by the academic institution's dedicated burnout prevention program, and, in the event that there is no help from existing employee support models, ${ }^{15}$ there is no better moment in the history of modern medicine than now to start one. For what it is worth, as always and everywhere, a group of volunteers who are willing to see patients pro bono will quickly appear; so why not start with one's own colleagues?

As the face of education continues to change, with pressing needs to offer various forms of teaching to our

\section{References}

1. In Spain, infection cases of COVID-19 are twice as high among female health workers. Source: UN Women calculation based on data from Spain's Ministry of Health: Analisis epidemiologico Covid-19, as of 30 March 2020. In: @unwomen, editor.

2. Boniol MM, M.; Xu, L.; Wuliji, T.; Diallo, K.; Campbell, J. Gender Equity in the Health Workforce: Analysis of 104 countries. Geneva: World Health Organization; 2019.

3. Wilson V. Exposed and Underpaid: Women Still Make less than Men, Including in Sectors Especially Affected by the Coronavirus [Internet]. Economic Policy Institute; 2020 [cited 2021 Jun 23]. Available from: https://www.epi.org/blog/exposed-and-underpaid-women-stillmake-less-than-men-including-in-sectors-especially-affected-by-thecoronavirus/.

4. Freizer S. COVID-19 and Women's Leadership: From an Effective Response to Building Back Better. New York: United Nations Entity for Gender Equality and the Empowerment of Women (UN Women); 2020.

5. Azcona GB A, Davies S, Harman S, Smith J, Wenham C. COVID-Spotlight on gender, COVID-19 and the SDGs: Will the Pandemic Derail HardWon Progress on Gender Equality? New York: United Nations Entity for Gender Equality and the Empowerment of Women (UN Women); 2020.

6. Parapid B, Alasnag M, Hayes SN, Samargandy S, Banerjee S, Alasnag M, et al. COVID-19 Impact on Women on Both Sides of the Frontline - the American College of Cardiology Women in Cardiology Section's International Working Group Perspective. Srpski Arhiv za Celokupno Lekarstvo. 2020;148(9-10):637-42. doi: 10.2298/SARH200828095P.

7. DeFilippis EM, Sinnenberg L, Mahmud N, Wood MJ, Hayes SN, Michos ED, et al. Gender Differences in Publication Authorship During COVID-19: A Bibliometric Analysis of High-Impact Cardiology Journals. J Am Heart Assoc. 2021;10(5):e019005. doi: 10.1161/JAHA.120.019005.

8. Alhurishi SA, Almutairi KM, Vinluan JM, Aboshaiqah AE, Marie MA Mental Health Outcomes of Healthcare Providers During COVID-19 students, committees that handle academic promotions have had plenty of time to consider involvement in frontline work-and more importantly lack thereof-as well as existing engagement in virtual teaching.

One solution is the creation of a new category of achievement points for candidates, especially for those who have actively participated in all pandemic-related activities from the beginning, as well as for colleagues who suffered from workplace-acquired COVID-19.

Even in the setting where groups of junior or midcareer academics are promoted together, it may be best to delay the promotion of a pandemic bystander for the benefit of an active participant.

This logic can only promote a healthier work environment in the long run, where no one will feel that they are being "left behind" because they are "unworthy".

Most importantly, as doctors, we know that, as long as there is a will, we tend to find a way, and, finally, if not us, then who?
Pandemic in Saudi Arabia: A Cross-Sectional Study. Front Public Health. 2021;9:625523. doi: 10.3389/fpubh.2021.625523.

9. Adibi A, Golitaleb M, Farrahi-Ashtiani I, Pirani D, Yousefi K, Jamshidbeigi Y, et al. The Prevalence of Generalized Anxiety Disorder Among Health Care Workers During the COVID-19 Pandemic: A Systematic Review and Meta-Analysis. Front Psychiatry. 2021;12:658846. doi: 10.3389/ fpsyt.2021.658846.

10. Takmaz T, Gundogmus I, Okten SB, Gunduz A. The Impact of COVID19-Related Mental Health Issues on Menstrual Cycle Characteristics of Female Healthcare Providers. J Obstet Gynaecol Res. 2021; Epub ahead of print. doi: 10.1111/jog.14900.

11. Shahbaz S, Ashraf MZ, Zakar R, Fischer F. Psychosocial, Emotional and Professional Challenges Faced By Female Healthcare Professionals during the COVID-19 Outbreak in Lahore, Pakistan: A Qualitative Study. BMC Womens Health. 2021;21(1):197. doi: 10.1186/s12905-021-01344-y.

12. Khan N, Palepu A, Dodek P, Salmon A, Leitch H, Ruzycki S, et al. Cross-Sectional Survey on Physician Burnout During the COVID-19 Pandemic in Vancouver, Canada: The Role of Gender, Ethnicity and Sexual Orientation. BMJ Open. 2021;11(5):e050380. doi: 10.1136/ bmjopen-2021-050380.

13. Marvaldi M, Mallet J, Dubertret C, Moro MR, Guessoum SB. Anxiety, Depression, Trauma-Related, and Sleep Disorders among Healthcare Workers During the COVID-19 Pandemic: A Systematic Review and Meta-Analysis. Neurosci Biobehav Rev. 2021;126:252-64. doi: 10.1016/j. neubiorev.2021.03.024.

14. Kouvari M, Souliotis K, Yannakoulia M, Panagiotakos DB. Cardiovascular Diseases in Women: Policies and Practices Around the Globe to Achieve Gender Equity in Cardiac Health. Risk Manag Healthc Policy. 2020;13:2079-94. doi: 10.2147/RMHP.S264672.

15. Lamb D, Simms A, Greenberg N, Withnall RDJ. Caring for the Carers: a COVID-19 Psychological Support Programme. BMJ Mil Health. 2021:bmjmilitary-2021-001854. doi: 10.1136/bmjmilitary-2021-001854. 